\title{
PLANTEAMIENTOS CONCEPTUALES DEL SUJETO EN EL ENTORNO VIRTUAL
}

\section{CONCEPTUAL APPROACHES OF THE SUBJECT TO THE VIRTUAL ENVIRONMENT}

\author{
Celia Corral Cañas \\ Universidad de Salamanca \\ celiuca@usal.es
}

Resumen: El sujeto virtual que circula por la red y habita sus distintas regiones tiene la oportunidad de reproducir su propia identidad o de generar máscaras desde la cuales actuar y conocer a otros internautas. Ante el clima de aparente libertad del nuevo medio electrónico, las posibilidades de representación narrativa oscilan desde la invisibilidad, el enmascaramiento y el disfraz, hasta la hipervisibilidad más "extimista", pasando por todo tipo de gradaciones de autoficción e identidades colectivas. El presente artículo analiza distintos planteamientos de intelectuales contemporáneos con el objetivo de mostrar una visión panorámica sobre la representación del sujeto en el entorno digital. La metodología empleada consiste en la exploración de los diferentes puntos de vista desde una perspectiva práctica y teórica sobre la cuestión abordada. Los resultados demuestran la diversidad de modos de generación de identidades en la red y la tendencia hacia la representación real o autoficticia con la consecuente exposición de la identidad.

Palabras clave: Planteamientos conceptuales, subjetividad, identidad, cíborg, extimidad, hipervisibilidad, autoficción, enmascaramiento, representación, entorno virtual
Abstract: The virtual subject that circulates through network and lives their spaces has the opportunity to play his own identity or create masks from which to act and to meet other surfers. In the environment of apparent freedom of the new electronic medium, the possibilities of narrative representations fluctuate from the invisibility, masking and disguise, to the more "extimist" hypervisibility, going through all kinds of gradations of autofiction and collective identities. The present article analyzes different approaches of contemporary intellectuals with the aim of showing a panoramic view on the representation of the subject in the digital environment. The methodology for this study is the exploration of the different points of view from a practical and theoretical perspective. The results confirm the diversity of modes of identity generation in the internet network and the tendency to real or autofictional representations with the consequent exhibition of the identity.

Keywords: Conceptual settings, subjectivity, identity, cyborg, extimity, hypervisibility, autofiction, masking, representations, virtual environment 


\section{INTRODUCCIÓN}

The Internet doesn't steal our humanity, it reflects it. The Internet doesn't get inside us, it shows what's inside us.

Josh Rose

Este estudio explora diversos abordajes de la reproducción de la subjetividad en internet, desde la fantasía de las posibilidades más artificiosas hasta la realidad de aquellas representaciones más fieles a la verdad o aquellas que combinan con relativa verosimilitud elementos biográficos y elementos simulados. Por último, se atiende también a las manifestaciones colectivas de identidades comunes que emergen gracias a las opciones comunicativas que ofrece el entorno virtual.

La metodología utilizada se basa en la observación de esta cuestión desde una perspectiva teórica a partir de la lectura de pensadores contemporáneos de relevancia en este ámbito (Broncano, Torras, Žižek, Zafra, Hernández-Navarro, Han, Castro, Fernández Porta, Sibilia, Imbert o Castells, entre otros) y en la exploración del propio medio electrónico, con el propósito de compartir una reflexión general de las distintas relaciones entre el "yo" real y su reflejo en internet.

En cada viaje ciberespacial que protagonizamos cotidianamente podemos descubrir la abundancia de material personal de la población digital. Este muestrario de rastros y sendas actúa como una representación de aquellas imágenes que deseamos manifestar en la red.

En la Galaxia Internet la subjetividad alcanza nuevas peculiaridades por la fluidez que caracteriza los movimientos de los internautas, tal y como expresa N. Katherine Hayles:

Figuración de la subjetividad virtual

El Sujeto Oral: Fluido, cambiante, situacional, disperso, contradictorio.

El Sujeto Escrito: Fijo, coherente, estable, idéntico a sí mismo, normalizado, descontextualizado.

EI Sujeto Virtual: formado a través de las interfaces dinámicas con los ordenadores.

Cuando la interfaz es un teclado y la pantalla, el espacio pertenece al ordenador, el flujo al usuario.

Las fronteras corporales extendidas o interrumpidas a través de la coherencia propioceptiva formada en conjunción con las interfaces de los ordenadores (2004: 69).

En un primer momento el sueño electrónico de ese flujo del usuario cíborg se acercaba a la posibilidad de generar nuevas identidades en un baile de máscaras carnavalesco que podría disfrutar -o no- de cierta verosimilitud. Sin embargo, junto al juego de alternar subjetividades en las relaciones con los otros y de experimentar desde nuevos avatares la construcción de un nuevo "yo" más o menos alejado al real, coexisten hoy la hipervisibilidad más pornográfica, una reproducción fiel de la persona con una concreción y un realismo abrumadores, y la visibilidad maquillada, en una materialización de lo real mediada, adulterada, autoficticia. 


\section{Diferentes manifestaciones de la subjetividad en el entorno ciberespacial}

\subsection{Evanescencia y nuevas identidades}

Para la profecía del New Age en internet se reformula la teoría platónica: el cuerpo se separa del alma y muere atrapado en sus propias limitaciones terrestres, mientras el alma vuela libre en el éter intangible. En la inmersión al simulacro virtual se produce una escisión de lo espiritual y lo material y su consecuente abandono de lo físico. Con esta experiencia convive el uso de las nuevas tecnologías desde perspectivas carnales, desde la pornografía como manifestación más evidente, hasta las distintas fantasías sexuales que surgen con la máquina y que conforman toda una tradición erótica. Según Mark Dery, "el auto erotismo futurista arrastra al mecanoerotismo a su desenlace fatal: la unión ciborgiana de la carne y el mecanismo" (1995: 216); y cita a K.W. Jeter para aludir al "viejo sueño guarro de la ciencia ficción: el coño mecánico" (1995: 219). El universo sexual está inundado de relaciones ciborgianas de todo tipo, hasta convertirse estas en un lugar común dentro del imaginario del erotismo de nuestro tiempo.

Por otra parte, aquellas dicotomías dominantes en el constructo cultural contemporáneo que empezaban a sufrir la crisis de la disolución de fronteras y de la deconstrucción de absolutos en la posmodernidad en el entorno digital de la actualidad afectan ya a la propia entidad física del sujeto, en la manera en que

la filosofía ciborg pone en cuestión las dicotomías entre medio y fin, entre cuerpo y prótesis, entre naturaleza y artificio. La cultura material es el entorno en donde estas dicotomías se disuelven (Broncano, 2012: 28).

Las subjetividades, por lo tanto, se escinden y se complejizan, y todas las certezas hasta ahora hegemónicas entran en cuestionamiento para desembocar en el entorno de lo postbiológico y postgenérico. De este modo, en internet eres quien quieres ser, construyes tu propia concepción, tu propio perfil y tu propio rostro, sin prejuicios ni ataduras físicas y sexuales. En este sentido resulta reveladora la siguiente reflexión de Meri Torras:

Internet nos descubre seres transnarracionales, es decir, en nuestra condición de seres no racionales, sino narracionales (que se narran) en relación, en perpetuo tráfico y movimiento. El movimiento electrónico (e-motion) puede contribuir favorablemente a la inscripción de un placer -una emoción-diferente de los hegemónicos, en el mismo proceso de canalización de identidades que re-construyen mentalmente el estigma de derivado y subalterno que lo han caracterizado en la tradición dominante (2005: 154).

En internet el retrato mental de la persona con la que interactúas se traza a partir de la narración: nuestro discurso es nuestra principal imagen. El contacto se produce así a través de las encrucijadas de semblanzas verbales y de diálogos en continua formación. Esta construcción de la imagen y la identidad a voluntad del propio internauta hace posible desde el enmascaramiento más sutil hasta la creación de falsas identidades. En este sentido, encontramos tanto suplantaciones de identidades de otras personas, como invenciones de nuevas identidades.

Con respecto a las suplantaciones de identidades, la facilidad para crear cuentas en las redes sociales viabiliza la utilización de nombres conocidos por parte de usuarios anónimos. De esta manera, se generan perfiles falsos motivados por diversos intereses: desde la mera intención de homenajear a la persona aludida, como es el caso 
de las cuentas de personalidades de otras épocas, en las que no se presupone, por tanto, intención de engaño, hasta el deseo de ridiculizarla, conseguir hacerse pasar por ella y ganar seguidores e, incluso, obtener fines lucrativos, como sucede con algunos famosos del ámbito de la política y de la cultura.

La simpleza y rapidez para crear cuentas que ofrece la red posibilita también la emergencia de invenciones de nuevas identidades. Una muestra sería el famoso blog de Amina Arraf, una mujer siria lesbiana y activista que utilizaba su bitácora como una vía de expresión para reflejar su dolorosa experiencia en la guerra de Siria y para luchar por sus derechos. Amina Arraf llegó a conmocionar a miles de personas, concedió, incluso, entrevistas a la prensa internacional y se convirtió en portavoz de las víctimas sirias y de la comunidad LGTB de la zona. Sin embargo, tal y como se descubrió meses después, en realidad se trataba de un personaje inventado con admirable verosimilitud por un norteamericano residente en Edimburgo llamado Tom MacMaster (Prieto, 2011: web). Por supuesto, el acto de falsear identidades no es exclusivo de internet. En el mundo analógico también existen testimonios que se presentan y se reciben como reales y autobiográficos pero que han sido diseñados para un público desde una subjetividad artificial, como sucede con las misery memoirs, obras que narran experiencias trágicas que son planteadas como vivencias reales por una estrategia de marketing y entre las que hay, en cambio, constancia de casos de falsificación literaria (Pron, 2014: 159).

El deseo de mostrar como real un sujeto ficticio transciende, por consiguiente, los límites de la red y está presente en diversos estadios, pero es destacable la multiplicidad de opciones que el contexto virtual deja al alcance de cualquier internauta. Además, en el espacio virtual la estructura física del individuo no tiene lugar y, por el contrario, se recupera el concepto del "sujeto descentrado' deconstruccionista" (Žižek, 2010: 152). Esta realización del sujeto deconstruccionista parece muy viable en este contexto en el que rige "la idea de post-cuerpo" (Zafra, 2010: 85) y sus consecuencias afectan a todas las áreas de la psicología humana.

En relación con la idea del post-cuerpo y con la autoconfiguración identitaria que el sujeto produce en la red son destacables los conceptos de "rostrificación" y "contrasexualidad" que Israel Roncero explora con respecto a la evolución en el retrato de mundo que se establece conforme a un sujeto creador y un personaje simbólicamente creado, desde "El origen del mundo" de Courvet, en 1866; pasando por "El origen de la guerra" de Orlan, en 1989; hasta un tercer ejemplo de nuestra época, que sería una imagen anónima colgada en Tumblr en 2012 y que consiste en un "autopornorretrato" de un usuario cualquiera de redes sociales (2012). La parte del cuerpo elegida como imagen representativa concreta la siempre compleja y confusa identidad, funcionando, así, como un símbolo cultural. Una vez superado el valor capital del rostro, dado que "la época de Facebook y Photoshop hace del "rostro humano" una faz que se disuelve por entero en su valor de exposición" y "la faz (face) es el rostro expuesto sin "aura de la mirada"” (Baudrillard, 1983: 28), el internauta se halla en la situación de encontrar o inventar nuevos espacios de identificación, en los cuales la representación será autorrepresentativa y el simbolismo metasimbólico:

Tras asumir la capacidad de distanciamiento y extrañamiento respecto al cuerpo de uno mismo, que favorecen las nuevas tecnologías, el sujeto de las redes sociales resignifica las cartografías anatómicas mediante la combinación de estrategias de rostrificación y contra-sexualidad. A través de una política contra-sexual, el sujeto de las redes sociales trata de redescubrir el valor sexual de todos los órganos del cuerpo, al no limitarse a mostrarnos el pene o la vagina como soportes de su 
reclamo identitario/sexual, sino sobre todo la axila y el ano; en muchas ocasiones el pecho o los pechos, la espalda, la pierna, el pie, o incluso órganos "prostéticos", como un iPod [...] o una guitarra eléctrica [...] Finalmente, esos "nuevos" órganos sexuales consiguen operar como sinécdoques de la identidad, siendo el eje central del autorretrato porno del sujeto en red, y la partes del cuerpo que, tras la remodelación de nuestros regímenes escópicos, aprovechando el potencial de intervención de las redes sociales, el sujeto de las redes sociales decide poner en circulación en el espacio público, como gerentes de una identidad seductora (Roncero, 2012: 95).

La imagen que seleccionamos para acompañar a nuestro avatar en cada una de nuestras intervenciones en internet (redes sociales, foros, chats, blogs y otros espacios) concretiza la abstracción, si bien no necesariamente de lo que somos, al menos sí de lo que deseamos comunicar ser. En el propósito de estos autorretratos de transmitir nuestra voluntad de definirnos las manifestaciones de algunas zonas corporales inusualmente concebidas como representadoras de personalidad se asocian con la idea de la contrasexualidad, especialmente operable en la esfera virtual.

Para Javier Echeverría el vínculo entre espacio electrónico y la sexualidad se enlaza con la desanimación del cuerpo y la nueva concretización del alma en un entorno abstracto y habla del "carácter sexuado/ no sexuado" como "otra nota diferencial que distingue el tercer entorno de los otros dos" (1999: 69). En este tercer entorno la representación sustituye a la presencia y cada internauta actúa como demiurgo de sí mismo. Este método es especialmente propicio para la expresión de nuevas identidades sexuales, para la alternación de género o de sexo, lo que se denomina "MorF", como

abreviatura de "male or female" "masculino o femenino" y un juego de palabras sobre el "morphing", una técnica infográfica que consiste en convertir una imagen en otra (Dery, 1995: 229).

Tanto desde el punto de vista del deseo de reencontrarse, como desde el del juego o el entretenimiento, la imaginación y la empatía de esta nueva vida paralela para el "MorF" conllevan el engaño y la probable frustración para aquellos con quienes se interactúe. En cualquier caso, la naturaleza no figurativa de internet posibilita la conversión de la persona en personaje(s).

La sexualidad en la red aborda, por lo tanto, desde el cibersexo y las visiones pornográficas más realistas hasta el enamoramiento que transciende lo físico y lo carnal para centrarse en la unión espiritual, intelectual, "Ideal".

\subsection{Materialización, extimidad e hipervisibilidad}

En contraposición al planteamiento platónico de las relaciones en la red, aparece una perspectiva que defiende la asombrosa materialización de lo abstracto. Miguel Á. Hernández-Navarro advierte las siguientes consideraciones:

Podría parecer cierto que, en efecto, todo lo sólido se ha disuelto en el aire y que estamos en medio de un mundo que tiende a lo inmaterial. Sin embargo, a poco que lo pensemos, nos daremos cuenta de que ese proceso de desmaterialización y compresión espacio-temporal es tan solo una ficción. Una ficción imposible. Una ficción que sólo funciona si se evita la materia, si no aparecen los cuerpos. [...]

Sin duda, la desaparición del cuerpo y su transformación en código habría sido la culminación de la utopía moderna. Un sujeto incorpóreo capaz de viajar por el ciberespacio a través de la pantalla. Información pura, sin vísceras ni órganos. Así 
que el cuerpo real, pesado y material, se convierte en el lastre más importante de la sociedad hipermoderna, en la mancha que perturba el régimen de las imágenes. [...]

No hay civilización más material que la nuestra, por mucho que los discursos caminen hacia la desmaterialización. El ritmo del progreso deja a su paso pilas de escombros. [...]

La cuestión de la obsolescencia, la fascinación por los objetos, tecnologías y modalidades de experiencia expulsadas del tiempo se ha convertido en algo central en la cultura contemporánea (2012: 215-123).

A pesar de todas las metáforas de fluidez y evanescencia del mundo contemporáneo - la modernidad líquida de Bauman, el mundo simulacral de Baudrillard, la sociedad transparente de Vattimo, la metabolización de la materia de Virilio (HernándezNavarro, 2012: 113)-, existe un interés creciente en lo material, en lo concreto. Nos encontramos inmersos en la gran era del culto al cuerpo, del fetichismo y del elogio a las extravagancias ornamentales y a la superficialidad perfeccionada gracias a la intervención técnica. Y si la ciencia opera en función de la estética, ¿dónde queda el espíritu de lo etéreo, de lo espiritualmente abstracto?

Por otra parte, en oposición a la naturaleza evanescente, abstracta y global del gran medio de "autocomunicación de masas" (Castells, 2009: 102), Ernesto Castro revela el carácter provinciano con que los internautas nos relacionamos en la red:

Reconozcámoslos: aquellos que siguen hablando de Internet en términos de liquidez y/o impersonalidad bien no han abierto una cuenta de Facebook en su vida, bien profesan un gran respeto por sus más directos maestros" (2011: 36-37).

Y alude al pensamiento de Eloy Fernández Porta:

Los ciudadanos que se formaron durante el postmodernismo vivieron bajo la égida de una idea muy extendida: "todo lo sólido se disuelve en el aire". Creo que el auge de la época digital, aunque también trae consigo sus disoluciones y sus disipaciones, nos enfrenta con una condición distinta, contrapuesta: "todo lo etéreo se consolida en la red". Cosas etéreas: amistades, vínculos, deseos factores que adquieren en la web una dimensión contractual -y se articula en estructuras con frecuencia bien visibles- (Fernández Porta, 2010: 235).

En esa materialización de lo abstracto se manifiesta también una tendencia a cosificar y a numerar y cuantificar aquello que por definición parecería incalculable:

La palabra "digital" refiere al dedo (digitas), que ante todo cuenta. La cultura digital descansa en los dedos que cuentan. Historia, en cambio, es narración. Ella no cuenta. Contar es una categoría poshistórica. Ni los tweets ni las informaciones se cuentan para dar lugar a una narración. Tampoco la timeline (línea del tiempo) narra ninguna historia de la vida, ninguna biografía. Es aditiva y no narrativa. El hombre digital digita en el sentido de que cuenta y calcula constantemente. Lo digital absolutiza el número y el contar. También los amigos de Facebook son, ante todo, contados. La amistad, por el contrario, es una narración. La época digital totaliza lo aditivo, el contar y lo numerable. Incluso las inclinaciones se cuentan en forma de "me gusta". Lo narrativo pierde importancia considerablemente. Hoy todo se hace numerable, para poder transformarlo en el lenguaje del rendimiento y de la eficiencia. Así, hoy deja de ser todo lo que no puede contarse numéricamente (Han, 2014: 60). 
El interés por plasmar autorretratos más o menos realistas y por contar lo incontable es cada vez más frecuente en las ágoras sociales como los blogs o las redes sociales. Lejos de tratar de universalizar ideas compartidas, publicamos nuestras experiencias mínimas, convirtiendo el gran medio de lo global en un repertorio de anécdotas, en analogía con la apuesta por lo fragmentario, por el dietario, por lo cotidiano de nuestro entorno posmoderno.

A pesar de conocer la potencialidad del anonimato y de haber recibido un sinfín de advertencias sobre el cuidado de la intimidad, perdemos la ambición del enmascaramiento y convertimos los rincones del ciberespacio por los que transitamos de nuestras propias imágenes. Este ejercicio ha derivado en el terreno del arte, con algunas iniciativas innovadoras como los famosos daily photo projects: las series de instantáneas de una misma persona tomadas diariamente que conforman un vídeo secuencial que refleja visualmente una vida y que se constituyen como

alegorías de la vida que se insertan en la tradición cultural convencionalizada occidental, desarrollando y renovando estos temas gracias al empleo de los medios digitales de captura y tratamiento de la imagen (Vives-Ferrándiz, 2009: 17).

El primer daily photo project fue la obra del fotógrafo Jonathan K. Keller, iniciada en 1998, titulada The adaption to my generation (a daily photo project). En 2000 el fotógrafo Noah Kalina comenzó Everyday con la misma intención: capturar cada día de su vida hasta su muerte. Al año siguiente Ahree Lee, diseñadora gráfica y cineasta experimental, se embarcó en la misma aventura, en una serie titulada Me. Por último, Arno Klein está construyendo un proyecto similar pero con la diferencia de que la retratada no es ella misma, sino su hija, Ellora, y las fotografías comienzan desde el mismo día de su nacimiento, por lo que, si el proyecto culmina, se tratará de la primera vida fotografiada diariamente. El componente artístico de estas obras de work in progress ha sido reconocido por el público y por algunos sectores de la crítica. Así, Everyday ha formado parte de exposiciones y actualmente está expuesto en el Austin Museum of Modern Art, además de haber recibido una gran expectación popular, como demuestra el dato de haber sido uno de los diez vídeos más vistos en Youtube en 2006 o el hecho de haber sido parodiado por The Simpsons (Vives-Ferrándiz, 2009). Independientemente del sentido artístico de estas expresiones (auto) biográficas, parece quedar en evidencia la exposición al desnudo de nuestras vidas en la pantalla.

Con excesiva frecuencia nos "enseñamos" en la red con nuestros propios datos y de manera indiscriminada, generamos avatares a nuestra imagen y semejanza -literal o relativamente- y desaprovechamos la inmaterialidad del medio virtual para ser o manifestar ser los que no somos, tal y como explica Martín Prada:

La red se ha llenado de presencias de personas concretas, con nombres y apellidos, con detallados perfiles, que escriben en blogs, que comparten las cosas que les gustan en redes sociales, que tratan de interactuar con otros sujetos a través de gustos y afinidades comunes y que desean hacer de si mismos en un espacio abierto a múltiples interacciones sociales $y$ afectivas posibles.

Nada de narraciones imaginarias, de historias inventadas. Nada de avatares ni sustitutos de los cuerpos en el espacio virtual, sino detallados perfiles de cuerpos y personas reales, con detalladas biografías, con abundantes imágenes de momentos de sus auténticas vidas, tratando de demostrar que son capaces de tener "una vida propia" (2012: 79). 
Nuestra apuesta por ser nosotros mismos, a pesar de las alteraciones voluntarias y del "postureo" generalizado, en un espacio de por sí indeterminado, resulta especialmente sorprendente: "La técnica aparece [...] como expresión del horizonte de lo posible y, junto con él, el de la nada y el vacío: podemos serlo "todo", pero no somos nada", de lo que se concluye: "La técnica nos muestra lo que somos: sólo una posibilidad de ser" (Esquirol, 2011: 39). En el afán por localizarnos y dejar todas las huellas que estén a nuestro alcance para ser encontrados entronca con la idea de la visibilidad como signo de existencia, en tanto en cuanto "somos nuestras representaciones. [...] Nuestra misma existencia consiste en las imágenes que nos hacemos de nosotros mismos" y, por consiguiente, "lo peor que puede sucedernos es que no haya representaciones de nosotros" (Scott Momaday, recogido por Sanyal, 2012: 11). Después de fantasear con el atractivo juego carnavalesco del disfraz, deseamos trasladar nuestra visión de nosotros mismos al mundo, tal vez como una huida desesperada de la soledad, como una búsqueda personal de la identidad.

Estas dos vías de representación se sintetizan en la dicotomía de "pliegue de aire"/ "pliegue de agua":

Los pliegues de agua, ajustan y revelan el cuerpo mejor que la desnudez. Así, los pliegues de aire pueden dibujar un ser inventado pero los mojados se convierten tan sólo en una pantalla de protección para mostrar la realidad más "real" y obscena (Zafra, 2001: web).

Esta actitud se integra en el fenómeno de la "extimidad" (Sibilia, 2008) y de la "hipervisibiliad" (Imbert, 2010), de la tendencia a la exteriorización al ágora pública mediática de los rincones interiores que hasta ahora se han considerado íntimos y privados. Esta "pornografía del sentir" (Imbert, 2008) es extrañamente frecuente y abundante, dado que la persona que escribe y que se muestra desconoce el público potencial que puede estar mirando al otro lado de la pantalla y, por tanto, no es consciente del alcance real de su intervención. La "extimidad", que se ha convertido en una forma de vida para muchas personas mediáticas, repercute en la propia identidad: la persona se convierte a sí misma en información pública, con las secuelas espirituales que este hecho puede tener sobre su vida. Asimismo, se difumina la frontera entre el ámbito profesional y el personal, en una transformación hacia una "sociedad confesional" (Bauman, 2012: 256) y hacia una "sociedad expuesta" (Han, 2013: 29) donde "cada sujeto es su propio objeto de publicidad" (Han, 2013: 29), de tal manera que "Todo se mide en su valor de exposición. [...] Todo está vuelto hacia fuera, descubierto, despojado, desvestido y expuesto" (2013: 29). La consecuencia de este comportamiento social es la desaparición de la esfera privada, debido a que "no hay ninguna esfera donde yo no sea ninguna imagen" (Han, 2014: 14-15). Esta circunstancia incide, para Han, en la conversión de nuestro mundo en un panóptico en el que cada individuo es a la vez y por propia decisión víctima y victimario:

Hoy, el globo entero se desarrolla en pos de formar un gran panóptico. No hay ningún afuera del panóptico. Este se hace total. Ningún muro separa el adentro y el afuera. Google y las redes sociales, que se presentan como espacios de la libertad, adoptan formas panópticas. Hoy, contra lo que se supone normalmente, la vigilancia no se realiza como ataque a la libertad. Más bien, cada uno se entrega voluntariamente a la mirada panóptica. A sabiendas, contribuimos al panóptico digital, en la medida en que nos desnudaos y exponemos. El morador del panóptico digital es víctima y actor a la vez. Ahí está la dialéctica de la libertad, que se hace patente como control (2013: 94-95). 
A pesar de la trágica perspectiva de Han, la hipervisibilidad en internet es un proceso espontáneo y generalizado. Esta "extimidad" produce a su vez la localización en el gran espacio desterritorializado por definición:

Cada vez hay más pruebas que sugieren que Internet potencia la glocalización, esto es: la adopción de tecnologías globales para su uso local. Es más, se diría que se está produciendo una regresión a una suerte de materialidad audiovisual de los vínculos, a una suerte de regionalismo cibernético de las relaciones

\section{$[\ldots]$}

La famosa aldea global pronosticada por Marshall McLuhan siempre tuvo más de aldea que de cualquier otra cosa (Castro, 2011: 39).

En nuestro paso por la esfera evanescente fomentamos la materialización en lo abstracto, la construcción de cuerpos sólidos, concretos, "reales". Slavoj Žižek afirma:

Estamos lejos, pues, de lamentar la pérdida de contacto con los otros "reales", de carne y hueso, como consecuencia de nuestra entrada en el ciberespacio, donde no encontramos más que fantasmas digitales: nuestra idea es más bien que el ciberespacio no es lo bastante espectral (2006: 255).

De esta manera, a la cuestión tan estudiada de la deshumanización de la persona se le añade la de la humanización de la red, en un juego de compensación y equilibrio en la simbiosis de mundos.

\subsection{Repercusiones sociales y construcciones de identidades colectivas}

La proyección constante de la imagen personal en un medio horizontal y abierto, sin instancias legitimadoras que filtren o cataloguen cada publicación, en el que, de hecho, la democratización es una de sus particularidades más distintivas se enfrenta al peligro de no cumplir su propósito comunicativo o de cumplirlo de un modo diferente al deseado por el emisor. Lee Siegel se refiere así a la "megademocracia", al "giro fatídico de la democracia" (2008: 83) y a "una burda caricatura del igualitarismo" (2008: 146) y asevera:

Usted se ha convertido en el centro del espectáculo que tradicionalmente ayudaba a los telespectadores a evadirse. El entretenimiento solía ser "escapista". Ahora parece que todos los que alguna vez se escaparon hayan sido perseguidos, acorralados y devueltos a sus propios egos (2008: 116-117).

El propósito evasivo de la ficción en la esfera virtual se ha convertido en un objeto de consumo del propio usuario quien, en la publicación de sus discursos e imágenes, se traslada al lugar del espectáculo, en una voluntaria conversión de sujeto a objeto dominada por la ilusión de (auto)visibilidad. Esta democratización podría conllevar repercusiones negativas que, según define Mario Perniola en su ensayo Contra la comunicación, son antidemocráticas y conducen a la ignorancia colectiva, ya que "una sociedad en la que tanto la aspiración a lo arduum et difficile como la capacidad de admiración han desaparecido, no puede ser una sociedad culta ni democrática" (2006: 103-104).

Sin embargo, el deseo de emular la vida propia en las regiones electrónicas lleva a pensar en la búsqueda de contactar con el otro que domina las relaciones sociales y que, como se ve, va más allá de los medios y de sus cualidades. Esta búsqueda a veces desemboca en encuentros que, gracias al amplio alcance de internet como medio de comunicación, se materializan en movimientos importantes y producen cambios cualitativos en la sociedad. La conversión del sentir colectivo en una ac- 
ción comunitaria comprometida correspondería al concepto de "identidad proyecto", según la terminología de Manuel Castells. La "identidad proyecto" es una alternativa diferente a la "identidad legitimadora" que imponen las instituciones correspondientes en cada contexto, y también a la "identidad de resistencia", propia de los actores estigmatizadores, que carece de viabilidad de implantación:

Una identidad proyecto es precisamente esto: no una proclamación utópica de sueños, sino la lucha por imponer modos alternativos de desarrollo económico, sociabilidad y gobierno. Existen embriones de una identidad proyectos europea y, probablemente, sólo si estos embriones encuentran expresión política, el proceso de unificación europea acabe lográndose (2001: 403).

De este modo, la identidad proyecto nace de los propios actores sociales, se desarrolla en los materiales culturales y derivaría en una auténtica transformación social.

En las primeras décadas del siglo xxi se han producido revelaciones de distintas identidades proyecto que han prosperado gracias a la red, como la primavera árabe, dentro de la cual tuvieron una gran importancia plataformas como la red social Facebook, o, en el ámbito español, el movimiento denominado "15 M" o "Democracia real", protagonizado por personas en desacuerdo con algunos aspectos de la práctica del sistema democrático nacional. Otro movimiento de identidad proyecto que ha evolucionado a través del entorno virtual es el "ciberfeminismo" que, según Remedios Zafra, "actuaría como pieza clave para entender y valorar la posible acción feminizadora y reconstructiva de los nuevos espacios creativos y tecnológicos de la red" (2005: 133-134).

Estas expresiones de pensamiento conciben la esfera digital como un nuevo espacio en el que redefinir identidades colectivas, gracias a sus posibilidades de participación y divulgación, con el fin de transformar distintas situaciones sociales. La identidad proyecto vinculada a internet consigue, por tanto, más allá de los juegos identitarios personales, el poder de la fuerza en manifestaciones sociales de diversas índoles.

\section{Conclusiones}

La variedad de caminos genera una ambigüedad en las representaciones, que oscilan entre lo inventado y lo verdadero para quedarse, con más frecuencia, en este segundo lugar. El sujeto digital adopta, en cualquier caso, una nueva identidad: la del Homo Surfer, con su movimiento volátil, espontáneo y superficial, como "paradigma contemporáneo de la Modernidad Líquida" (Castro y Lareu, 2011: 110). Si bien toda apariencia es, de por sí, un posible enmascaramiento, el "yo" que fluye en el clima de absoluta libertad se reencarna en una relativa fidelidad que, sin embargo, tiene una propia identidad ciberespacial.

En esas interfaces dinámicas el sujeto cíborg se expresa y se construye según sus deseos, en una auto-representación que, a menudo, se acerca más a las fórmulas hipervisibles, extimistas y autoficticias que a la aventura del disfraz. Cabría preguntarse cuál es el valor de esa emisión de realidad en la esfera de la simulación, cuál es el límite entre realidad y simulación cuando ambas se producen de forma simultánea y constante.

La esfera digital, en conclusión, facilita los medios necesarios para construir cualquier tipo de avatar, desde los roles más alejados hasta la exacta y detallada realidad, identificándose así como una de las grandes singularidades, desde una perspectiva 
psicológica y social, del medio electrónico: la potencialidad libre e ilimitada de representaciones para el sujeto virtual y sus consecuentes encrucijadas. Dentro de esta amplia y heterogénea viabilidad de opciones, resulta sorprendente la tendencia al simulacro "real" en una exhibición que en ocasiones abusa del deseo de transparencia y que establece un paralelismo relativamente fiel de la imagen real.

El abandono de la fantasía neoplatónica y la apuesta por el regreso al "yo" y a una exteriorización deliberada conlleva la exposición de la identidad en un medio de alcance global, de manera que la comunidad conectada construye su propio "panóptico" voluntario del que hablara Han en el que cohabitan los reflejos y las vidas de los internautas, pero también hay construcciones de identidades colectivas que aprovechan las oportunidades comunicativas del medio para establecer redes comunitarias vinculadas con un compromiso común.

En la expresión narracional de la subjetividad íntima y colectiva, por tanto, los caminos son múltiples y destacan las iniciativas que exhiben la identidad, bien sea con un fin extimista o con un fin social, y cuya proyección repercute a los dos lados de la pantalla.

\section{Bibliografía}

Baudrillard, R. (1983). Las estrategias fatales. Barcelona: Anagrama.

Bauman, Z. (2012). Esto no es un diario. Barcelona: Paidós.

Broncano, F. (2012). La estrategia del simbionte. Cultura material para nuevas humanidades. Salamanca: Delirio.

Castells, M. (2001). La Galaxia Internet. Reflexiones sobre Internet, empresa y sociedad. Madrid: Areté.

- (2009). Comunicación y poder. Madrid: Alianza Editorial.

Castro, E. (2011). "Mallas de protección. La codificación del yo en la Era Comunicativa". VV.AA., Redacciones. Salamanca: Editorial Caslon, 19-41.

Castro, E. y Lareu J. (2011). "La gota que colma el vaso: encuentro con Zygmunt Bauman". Revista de Occidente $\mathrm{n}^{\circ}$ 364, 105-119.

Dery, M. (1998). Velocidad de escape. La cibercultura en el final del siglo. Madrid: Siruela.

Echeverría, J. (1999). Los señores del aire: Telépolis y el Tercer Entorno. Barcelona: Destino.

Esquirol, J. M. (2011). Los filósofos contemporáneos y la técnica. De Ortega a Sloterdijk. Barcelona: Gedisa.

Fernández Porta, E. (2010). €®O\$. La superproducción de los afectos. Barcelona: Anagrama.

Han, B-C. (2013). La sociedad de la transparencia. Barcelona: Herder.

- (2014). En el enjambre. Barcelona: Herder.

Hayles, N. K. (2004). "La condición de la virtualidad". Domingo Sánchez-Mesa (ed.), Literatura y Cibercultura. Madrid: Arco Libros, 37-72. 
Hernández-Navarro, M. Á. (2012). Materializar el pasado. El artista como historiador (benjaminiano). Murcia: Editorial Micromegas.

Imbert, G. (2008). El transformismo televisivo. Postelevisión e imaginarios sociales. Madrid: Cátedra.

- (2010). La sociedad informe. Posmodernidad, ambivalencia y juego con los límites. Barcelona: Icaria.

Jeter, K. W. (1984). Dr. Adder. Nueva York: Signet.

Martín Prada, J. (2012). Otro tiempo para el arte. Cuestiones y comentarios sobre el arte actual. Valencia: Sendema.

Perniola, M. (2006). Contra la comunicación. Buenos Aires: Amorrortu editores.

Prieto, M. G. (2011). "La bloguera lesbiana de Damasco, un heterosexual que vive en Escocia". El mundo, 13 de junio de 2011. Recuperado de http://www.elmundo.es/elmundo/2011/06/13/internacional/1307947493.html

Pron, P. (2014). El libro tachado. Prácticas de la negación y del silencio en la crisis de la literatura. Madrid: Turner.

Roncero, I. (2012). "La rostrificación del cuerpo abyecto en el entorno de las redes sociales". Caracteres. Estudios culturales y críticos de la esfera digital vol. $1 \mathrm{n}^{\circ} 1$, mayo 2012, 86-96. Recuperado de http://revistacaracteres.net/wp-content/uploads/2012/05/ Caracteresvol1n1mayo2012.pdf

Rose, J. "How Social Media Is Having a Positive Impact On Our Culture". Mashable, 23 de febrero de 2011. Recuperado de http://mashable.com/2011/02/23/social-media-culture/

Sanyal, M. M. (2012). Vulva. La revelación del sexo invisible, Barcelona: Anagrama.

Sibilia, P. (2008). La intimidad como espectáculo. Buenos Aires: Fondo de Cultura Económica.

Siegel, L. (2008). El mundo a través de una pantalla. Ser humano en la era de la multitud digital. Barcelona: Ediciones Urano.

Torras, M. (2005). "Matriz Hipertext/sexual. Internet como escenario de inscripción del sujeto posthumano". Laura Borràs (ed.), Textualidades electrónicas. Nuevos escenarios para la literatura. Barcelona: UOC.

Vives-Ferrándiz, L. (2009). "Una vida en imágenes: los daily photo projects y la retórica del instante". Imago. Revista de emblemática y cultura visual $\mathrm{n}^{\circ}$ 1, 7-26.

Zafra, R. (2001). "Habitares reversibles (de la mujer, el arte e Internet)". Mujeres que hablan de mujeres. Fotonoviembre 01. Recuperado de http://www.elviajero.org/mujeresque/_text.html

- (2005). Netianas. N(h)acer mujer en Internet. Madrid: Lengua de Trapo.

- (2010). Un cuarto propio conectado. (Ciber)espacio y (auto)gestión del yo. Madrid: Fórcola.

Žižek, S. (2006). Lacrimae rerum. Ensayos sobre cine moderno y ciberespacio. Barcelona: Debate.

- (2010). El acoso de las fantasías. Madrid: Siglo XXI. 